\title{
Dynamic Response Analysis Among Environmental Regulation, Technological Progress and Water Resource Consumption in China's Textile Industry
}

\author{
Yi Li ${ }^{1-3}$, Yihan Wang ${ }^{4}$, Lili Ding ${ }^{4}$, Linjiang $\mathrm{Ke}^{4}$, Weiqian $\mathrm{Ma}^{4}$, Yongliang Yang ${ }^{4,5 *}$ \\ ${ }^{1}$ East China Sea Institute/Center for Ecological Civilization of Yangtze River Delta ,Ningbo University, Ningbo, China \\ ${ }^{2}$ Fashion Department, Ningbo University, Ningbo, China \\ ${ }^{3}$ Silk and Fashion Culture Research Center of Zhejiang Province, Hangzhou, China \\ ${ }^{4}$ School of Economics and Management, Zhejiang Sci-Tech University, Hangzhou, China \\ ${ }^{5}$ Ecological Civilization Research Center of Zhejiang Province, Hangzhou, China
}

Received: 9 May 2019

Accepted: 25 September 2019

\begin{abstract}
The rapid development of the textile industry (TI) has led to serious water resource consumption. Driven by the demands of the green economy, improving the comprehensive management level of water scientifically and measuring the relationships among environmental regulations, technological progress and water resource consumption rationally in the TI are necessary in order to solve the water resource consumption problem and promote the transformation and upgrading the TI. We used decoupling theory to quantitatively analyze the decoupling relationship among environmental regulation, technological progress and water resource consumption from 2002 to 2015 in China's TI. We also constructed the dynamic response vector autoregressive model of China's industrial water source consumption to study the internal dynamic correlation from the perspective of time series. Analysis showed that the decoupling between water resource consumption and environmental regulation in the TI was strong in 6 years (2003, 2006, 2009, 2011, 2013 and 2015) and weak in 3 years (2002, 2004 and 2010). The decoupling between water resource consumption and technological progress is also strong in 6 years (2003, 2006, 2008, 2009, 2011 and 2015) and weak in 3 years (2007, 2010 and 2012). Overall, a longterm cointegration relationship is found among environmental regulation, technological progress and water resource consumption. The intensity of environmental regulation and the degree of technological progress positively affects the improvement in water resource consumption. Moderate enhancement in environmental regulation and improvement in technological progress can alleviate the issues of water resource consumption.
\end{abstract}

Keywords: textile industry, environmental regulation, technological progress, water resource consumption, decoupling

*e-mail: royyang@zstu.edu.cn 


\section{Introduction}

The textile industry (TI) is a traditional pillar industry in China and an important livelihood industry with evident international competitive advantages. It plays an important role in helping the market prosper, increasing employment, accelerating the urbanisation process and promoting the harmonious development of society [1]. In the new century, the total output value of China's TI has maintained steady growth. In 2015, the total output value reached 405.912 billion USD and an average annual growth of $13.36 \%$ compared with that in 2001. China's export of major textile products, including chemical fibre, yarn and cloth, ranks first in the world and shows a trend of continuous growth. Specifically, its share of the world total increased from $10.42 \%$ in 2000 to $38.60 \%$ in 2015 . However, the rapid development of the TI has resulted in serious water consumption. In 2015 , the total water consumption of China's TI reached 8488.29 Mt, ranking 7th and accounting for $4.1 \%$ of the total water consumption among the China's 41 key industries surveyed. The reuse rate of water in the TI was $65.21 \%$, which was considerably lower than the average of $89.61 \%$ in the corresponding key industries [2]. To transform the development of the TI from scale to quality and efficiency and reducing consumption has become a great challenge for China's TI.

With the increasingly severe situation of water resources, scholars have focused on water conservation in various industries. The traditional water resource management system has many uncertainties and risks and is complicated; thus, it needs to be improved regarding water resource consumption. Ruiz-Vanoye et al. [3] guides the understanding of different types of water optimization problems (including water resource planning, water quality management, water supply network, water distribution system, water flow and chemical transportation, and water distribution network). Through mathematical models, it is found that it is important to minimize construction cost, maintenance cost and water transport cost of the water supply pipeline. Yue et al. [4] improved the ability of the traditional industrial water resource management system to promote industrial water distribution under uncertain conditions by integrating operational research, uncertainty analysis and violation risk analysis methods. For example, the production of civil steel ships and machine-made paper and paperboard in Dalian City, China will be significantly decreased by 2020 , and the risk of chemical oxygen demand emissions will be the most significant. Tuan et al. [5] established a systematic water quality balance framework, quantified and distinguished the inflow, outflow and use of all man-made and natural water and proposed the importance of technological innovation in the process of water inflow and outflow. Li et al. [6] established an interval multi-objective programming model, which combines multi-objective programming and interval linear programming into a general programming framework in order to deal with the uncertainty and complexity of a water management system and solve the uncertainty of water allocation. This model also allows decision makers to adjust fuzzy target control decision variables for meeting multiple overall and interactive goals. Under different weather conditions that focus on reliability, the resilience and vulnerability of a water resource system were evaluated by Asefa et al. [7]. For industrial enterprises, the goal is to minimize the cost of resource utilization and reduce the consumption of water resources by strengthening the construction of industrial water networks (Ramos et al. [8]). Alnouri et al. [9] believed that the innovation of a water network integration technology can allocate reasonable water quality and quantity for different industrial water use units and achieve optimal control of freshwater utilisation and wastewater discharge. Geng et al. [10] constructed a model of comprehensive water resource management at the industrial park level, made an economic analysis of the water network and used it to optimise the water resources in the industrial park and seek potential water resource reuse among various industries. They also incorporated the model into the scale and cost of the wastewater recycling transportation system. Feasibility analysis showed that this method can save water and cost. Wang et al. [11] built a relaxation measure model based on the hypothesis of non-expected output of weak adjustability, studied the issue of water use efficiency and proposed that strengthening environmental policy orientation and water-saving technology level is the key to improving industrial water efficiency. Li et al. [12] studied the decoupling relationship between economic growth and resource consumption of the TI and its three subdivisions. They found that the industrial scale factor is the most important driving force for the increase in water consumption in the TI in China, whereas technological progress is the most important inhibitor. Furthermore, the industrial structure adjustment slightly influences water consumption. The authors suggested countermeasures for industrial water conservation. On the production frontier based on the DEA model, $\mathrm{Hu}$ et al. [13] constructed a target ratio index of water adjustment, obtained the efficiency of domestic and production water use under the framework of total factors and analysed the regional differences in water resource consumption. They concluded that a U-shaped curve relationship exists between water resource consumption and per capita income.

The discussion above indicates that analysing the influence of resource element in the industrial process on behalf of water resources, continuously optimising and improving the distribution of industrial water and utilising industrial water networks, is necessary for improving the water consumption of industrial parks or enterprises. The research has been extended to the demand for efficient industrial water technology and its environmental effects. Under the continuous strengthening of China's environmental regulation to 
promote water conservation in the $\mathrm{TI}$, the dynamic relationship between water resource consumption and environmental regulation in the TI and the effectiveness of the existing technological progress in reducing the total water intake in the TI has been studied only rarely. Thus, this work uses the decoupling model to demonstrate the dynamic evolutionary relationship among water resource consumption, environmental regulation and technological progress in the TI. The vector autoregressive (VAR) model is also used to test the internal mechanism that leads to the transformation of the relationship. Accordingly, countermeasures and suggestions to promote water conservation in the TI are proposed.

\section{Material and Methods}

\section{Tapio Decoupling Model}

Decoupling analysis refers to the construction method of Tapio decoupling index [14-16] to construct the decouple the model of water resource consumption in the TI, and the formula is:

$$
\theta_{t}=\frac{\% \Delta \text { water }}{\% \Delta \text { force }}=\frac{\%\left(\text { water }_{t}-\text { water }_{t-1}\right) \text { force }_{t-1}}{\%\left(\text { force }_{t}-\text { force }_{t-1}\right) \text { water }_{t-1}}
$$

...where $\theta$ is the decoupling elasticity; $t$ is the year; water signifies the index of water resource consumption in $t$; and force indicates the driving force, including the indicators of environmental regulation and technological progress.

The possibilities of the decoupling state are yielded and shown in Fig. 1, and they can be separated into eight types, from the most ideal 'strong decoupling' state to the least ideal 'strong negative decoupling'.
Compared with the other unfavourable degrees, the 'weak decoupling' state is more satisfactory, although it is not as advantageous as 'strong decoupling'.

\section{Dynamic Response Model}

The VAR model was proposed by Sims in 1980, and it is widely used in empirical research on dynamic change rules between variables [17-19]. The formula is shown as follows:

$$
X_{t}=\sum_{j=1}^{p} A_{\mathrm{j}} X_{t-j}+\varepsilon_{t}+\mathrm{c}
$$

...where $X_{t}$ refers to the time component vector; $p$ is the order of autoregressive lag; $A_{j}$ is the time series coefficient matrix; $c$ is a constant vector; and $\varepsilon_{t}$ is the white noise sequence and meets the following conditions: $E\left(\varepsilon_{t}\right)=0$, which indicates the average error is 0 ; $E\left(\varepsilon_{t} \varepsilon_{t}^{\prime}\right)=Q$, which indicates the error covariance matrix is $Q$; and $E\left(\varepsilon_{t} \varepsilon_{t-k}^{\prime}\right)=0$, which indicates the error term has no autocorrelation.

Firstly, the original variable sequence is subjected to the augmented Dickey-Fuller unit-roots test (ADF test) $[20-21]$ and the Phillips-Perron unit-root test (PP test) [22] to check for stability. If the original sample sequence is unstable but the sequence is stable after the $i$-th difference, then it follows the $i$-order single integer. If all test sequences follow single integration of the same order, then the VAR model can be constructed for a cointegration test [23].

The Engle-Granger cointegration test (EG test) method [24-25] was selected to further analyse the dynamic cointegration of the variable series. The ordinary least squares (OLS) method is used to carry out static regression tests on indexes of water resource consumption, environmental regulation, technological progress and water resource consumption in the TI.
Strong negative decoupling $\Delta$ force $<0, \Delta$ water $>0, \theta<0$
Expansive negative decoupling

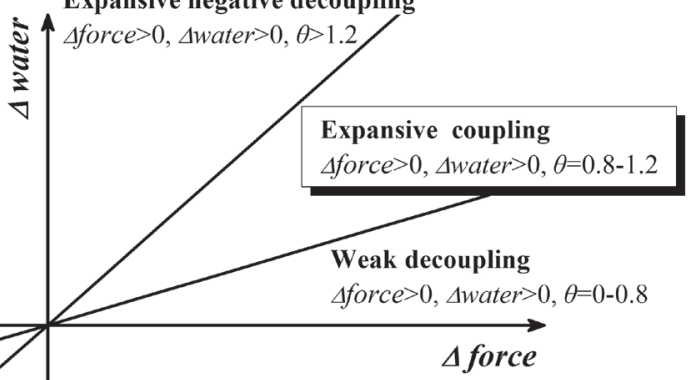

Strong decoupling

$\Delta$ force $>0$, wwater $<0, \theta<0$

Fig. 1. Decoupling coordinate diagram. 
This study also checks the single integral order of the sequence of residuals, which is measured in accordance with the stationary test procedure of the sequence. If the sequence is non-stationary, then no cointegration relationship exists between variables; otherwise, a cointegration relationship exists between variables.

On the basis of the cointegration relationship test, the generalised impulse response function [26-27] is selected to analyse the dynamic impact response situation among water resource consumption, environmental regulation and technological progress in the TI, and analyse whether a positive or negative effect exists among them. The impulse response function analyses its long-term dynamic relationship, that is, it verifies the characteristics of the current and future state changes in endogenous variables by applying the information shock of unit standard deviation to the disturbance term, and the formula is shown as follows:

$$
I\left(n, \delta_{k}, t-1\right)=E\left(x_{t+n} \mid \varepsilon_{k t}, t-1\right)-E\left(x_{t+n} \mid t-1\right)
$$

...where $\delta_{k}$ refers to the impact of the $k$-th variable, $n$ refers to the number of impact response periods and $t-1$ refers to the information available when the impact occurs. The impulse response function (IRF) value of the impact in period $n$ must be solved, that is, the difference caused by impact $\delta_{k}$ on expected value $x_{t+n}$ is considered.

The contribution level of environmental regulation and technological progress to the rate of the change in industrial water resource consumption is reflected by the variance decomposition of prediction. The process is described as follows: the mean square error (MSE) of prediction based on endogenous variables (water resource consumption) is decomposed into $m$ components in the system associated with each equation depending on their causes and the relative importance of measurement information to endogenous variables. The s-step prediction error of the model is

$$
\varepsilon_{t+s}+\varphi_{1} \varepsilon_{t+s-1}+\varphi_{2} \varepsilon_{t+s-2}+\ldots+\varphi_{s-1} \varepsilon_{t+1}
$$

MSE is expressed as follows:

$$
Q+\varphi_{1} Q \varphi_{1}^{\prime}+\ldots+\varphi_{s-1} Q \varphi_{s-1}^{\prime}=p p^{\prime}+\varphi_{1} p p^{\prime} \varphi_{1}^{\prime}+\ldots+\varphi_{s-1} p p^{\prime} \varphi^{\prime}{ }_{s-1}
$$

The formula above shows that the MSE of any endogenous variable can be decomposed into the impact contribution value of each variable. By calculating the ratio between the contribution of each variable and the total contribution, the relative importance of environmental regulation and technological progress on the impact of water resource consumption can be analysed.

\section{Data Source and Processing}

Considering the lag effect of environmental regulation and technological progress on water resource consumption and in accordance with relevant research literature, the lag period of environmental regulation and technological progress is defined as 1 year [28]. The water consumption data of the TI in China are from 2001 to 2015, and the data of environmental regulation and technological progress are from 2000 to 2014. The total water consumption data of the TI comes from the China Environmental Yearbook (2002-2006) and Annual Statistic Report on the Environment in China (2006-2015).

The strength measurement methods of environmental regulation mainly include single quantitative index measurements and a comprehensive quantitative index [29-31]. Comprehensive quantitative indicators can integrate multiple dimensions of quantitative indicators in the environmental field and can quantify the overall strength of environmental regulation more comprehensively than the single one.

In accordance with $\mathrm{Fu}$ et al. [32-34], environmental regulation can be calculated by the following equation:

$$
E_{i}=\frac{1}{n} \sum_{\mathrm{j}=1}^{n} Y S_{i j}^{s} \cdot \delta_{i j}, n=1,2, \ldots, m
$$

...where $n$ is the classification index, $Y S_{i j}$ represents the output indicators and $Y S^{S}{ }_{i j}$ is the standardised value. $\delta_{i j}$ refers to the weight of each single index, and the equation $\delta_{i j} Y S_{i j} / \overline{Y S}_{i j}$ expresses the ratio of the unit output $Y S_{i j}$ of output $\mathrm{j}$ of industry $i$ output $j$ to the average unit output $\overline{Y S}_{i j}$ of output $j$.

On the basis of the severity of various pollutants in China and the availability of data, this study selects four individual indicators to measure environmental regulation intensity: the wastewater discharge compliance rate; the sulphur dioxide removal rate; the comprehensive utilisation rate of industrial solid waste; and the dust removal rate, $n=4$.

The wastewater discharge compliance rate is the ratio between wastewater discharge compliance and industrial wastewater discharge, and the period of 2011-2014 of the rate is predicted by Fourier curve due to the data shortage. The sulphur dioxide removal rate is equal to the removal of industrial sulphur dioxide divided by the production of sulphur dioxide in the TI (the total removal and emissions). The comprehensive utilisation rate of solid waste is the ratio of the total amount of solid waste production and the comprehensive utilisation of previous storage to the comprehensive utilisation rate of solid waste. The dust removal rate is divided by the dust removal amount by the yield. These data are from the China Environmental Yearbook (2001-2006) and Annual Statistic Report on Environment in China (2006-2014). 
Measurement indicators of technological progress usually adopt quantitative indicators such as research and development (R\&D) input [35], total factor productivity [36-37] and patent quantity [38-40]. Given that the statistical data of R\&D input is limited in several years and the number of patents cannot objectively reflect the technological level of the industry, the total factor productivity is selected to measure the technological progress and measured by the Solow residual method of Luintel et al. [41]. According to the Cobb-Douglas production function: $y_{i t}=\alpha k_{i t}^{\alpha} l_{i t}^{\beta} y_{i t}$, the total factor productivity function is defined as:

$$
t f p_{i t}=\frac{y_{i t}}{k_{i t}^{\alpha} l_{i t}^{\beta}}
$$

...where $a$ and $\beta$ are the parameters of the production function. Referring to the research of $\mathrm{Lu}$ et al. [42-43], $a$ is 0.35 and $\beta$ is 0.4. $y_{i t}$ refers to the total output of each year, that is, the annual gross value, while $k_{i t}$ refers to the fixed capital stock in each year and is estimated by the perpetual inventory method [44]:

$$
K_{t}=I_{t}+\left(1-\delta_{i t}\right) K_{t-1}
$$

... where $\delta_{i t}$ represents the depreciation rate with a value of $4 \%$ according to $\mathrm{Wu}[45]$ and $l_{i t}$ represents the labour input level, that is, the average of the number of employees at the end of the year and the previous year. Considering the data shortage, the average number of people employed in 2012 is calculated by monthly data instead.

The data required for calculating the comprehensive index of technological progress are the fixed capital stock, the labour input level and the total output of each year. The data are from the China Statistical Yearbook (2001-2015), the China Industry Economy Statistical Yearbook (2000-2015), the China Environmental Yearbook (2001-2006) and the Annual Statistic Report on Environment in China (2006-2014).

\section{Results and Discussion}

\section{Decoupling Measurement and Analysis}

On the basis of Formula (1), Table 1 lists the decoupling relationships among environmental regulation, technological progress and water resource consumption in the TI from 2002 to 2015. Among the 14 calculation results, the decoupling between water

\begin{tabular}{|c|c|c|c|c|c|c|c|}
\hline \multirow[t]{2}{*}{ Year } & \multirow{2}{*}{$\begin{array}{l}\text { Change rate of } \\
\text { environmental } \\
\text { regulation }\end{array}$} & \multirow{2}{*}{$\begin{array}{l}\text { Change rate of } \\
\text { technological } \\
\text { progress }\end{array}$} & \multirow{2}{*}{$\begin{array}{c}\text { Change rate of } \\
\text { water resources } \\
\text { consumption }\end{array}$} & \multicolumn{2}{|c|}{$\begin{array}{l}\text { Decoupling index of water } \\
\text { resources consumption and } \\
\text { environmental regulation }\end{array}$} & \multicolumn{2}{|c|}{$\begin{array}{l}\text { Decoupling index of water } \\
\text { resources consumption and } \\
\text { technological progress }\end{array}$} \\
\hline & & & & $\begin{array}{l}\text { Index } \\
\text { value }\end{array}$ & Decoupling state & $\begin{array}{l}\text { Index } \\
\text { value }\end{array}$ & Decoupling state \\
\hline 2002 & 25.057 & 0.118 & 0.142 & 0.006 & Weak decoupling & 1.2008 & $\begin{array}{c}\text { Expansive negative } \\
\text { decoupling }\end{array}$ \\
\hline 2003 & 0.311 & 0.056 & -0.101 & -0.325 & Strong decoupling & -1.8044 & Strong decoupling \\
\hline 2004 & 0.711 & 0.054 & 0.188 & 0.264 & Weak decoupling & 3.5085 & $\begin{array}{c}\text { Expansive negative } \\
\text { decoupling }\end{array}$ \\
\hline 2005 & -0.139 & 0.153 & 0.150 & -1.080 & $\begin{array}{l}\text { Strong negative } \\
\text { decoupling }\end{array}$ & 0.9787 & Expansive coupling \\
\hline 2006 & 0.305 & 0.175 & -0.028 & -0.091 & Strong decoupling & -0.1596 & Strong decoupling \\
\hline 2007 & 0.114 & 0.214 & 0.103 & 0.901 & Expansive coupling & 0.4804 & Weak decoupling \\
\hline 2008 & -0.031 & 0.157 & -0.017 & 0.561 & Weak negative decoupling & -0.1094 & Strong decoupling \\
\hline 2009 & 0.131 & 0.367 & -0.003 & -0.026 & Strong decoupling & -0.0093 & Strong decoupling \\
\hline 2010 & 0.190 & 0.059 & 0.024 & 0.128 & Weak decoupling & 0.4141 & Weak decoupling \\
\hline 2011 & 0.205 & 0.128 & -0.166 & -0.810 & Strong decoupling & -1.2949 & Strong decoupling \\
\hline 2012 & -0.492 & 0.281 & 0.021 & -0.043 & $\begin{array}{l}\text { Strong negative } \\
\text { decoupling }\end{array}$ & 0.0753 & Weak decoupling \\
\hline 2013 & 0.111 & -0.032 & -0.026 & -0.232 & Strong decoupling & 0.7903 & $\begin{array}{l}\text { Weak negative } \\
\text { decoupling }\end{array}$ \\
\hline 2014 & 0.106 & 0.055 & 0.101 & 0.951 & Expansive coupling & 1.8449 & $\begin{array}{c}\text { Expansive negative } \\
\text { decoupling }\end{array}$ \\
\hline 2015 & 0.052 & 0.045 & -0.018 & -0.354 & Strong decoupling & -0.4056 & Strong decoupling \\
\hline
\end{tabular}

Table 1. Decoupling elasticity measurement results. 
resource consumption and environmental regulation intensity in the TI was strong in 6 years $(2003,2006$, 2009, 2011, 2013 and 2015) and weak in 3 years (2002, 2004 and 2010). In 2008, the intensity of environmental regulation and the intensity of water consumption in the TI declined, which indicated weak negative decoupling. In 2007 and 2014, the increase rate of environmental regulation intensity was higher than the change rate of water resource consumption in the TI, which indicated expansive coupling. The worst two years were 2005 and 2012, with a strong negative decoupling, a decline in the intensity of environmental regulation and an increase in gross water resource consumption in the TI. 2005 is the last year of China's tenth five-year plan (20012005). The output and export of China's textile industry have increased greatly after China's accession to the WTO in 2001. However, due to the lack of awareness of sustainable development and water-saving technologies, a large amount of water is used in the industrial production of export textiles and clothing. In 2012, it can be concluded that the main reasons for this are the transfer of backward production capacity in central and western regions, regional distribution, adjustment and optimization of the failure and size of the changing demand changes water resources during the process of the "East-to-West Mulberry Transfer" program.

The decoupling between water resource consumption and technological progress in the TI experienced a similar situation, that is, strong decoupling in 6 years (2003, 2006, 2008, 2009, 2011 and 2015) and weak decoupling in 3 years (2007, 2010 and 2012). 2013 showed weak negative decoupling. Although the change rate of technological progress decreased, the gross water resource consumption in the TI also decreased. The worst ones were expansive negative decoupling (2002, 2004 and 2014) and expansive coupling (2005), which were reflected in the increase in technological progress rate in the TI, but the gross water resource consumption was still increasing.

The analysis above indicates that the decoupling among water resource consumption, environmental regulation and technological progress in the TI from
2001 to 2015 is significant, and the following basic assumptions can be put forward:

Hypothesis $\mathrm{H}_{1}$ : The increase in the intensity of environmental regulation can trigger a reverse change in the gross water resource consumption in the TI, that is, environmental regulation can inhibit the increase in the gross water resource consumption in the TI.

Hypothesis $\mathrm{H}_{2}$ : Technological progress has a positive effect on reducing the gross water resource consumption in the TI, that is, technological progress can effectively inhibit and control the increase of the gross water resource consumption in the TI.

VAR model is used to further study the internal influence mechanism for testing the correctness of the above-mentioned hypothesis.

\section{Dynamic Response Analysis}

\section{Cointegration Regression Test}

In this study, the water resource reuse rate $(i)$ in the TI is introduced as the proxy variable of water resource consumption in constructing the VAR model between water resource consumption in the TI and environmental regulation, technological progress and water resource reuse rate in the TI. The optimal lag order is determined by Stata 12.0. On the basis of the Akaike information criterion (AIC), Schwarz information criterion (SIC), fitting level of estimation equation and coefficient significance, the optimal lag order is determined to be 2. Considering the time series characteristics of each variable from 2001 to 2015, a stationary test was carried out.

To further determine the stationarity of the firstorder difference sequence of all variables in the sample period, ADF and PP tests are conducted on all variables and first-order differences, and the results are shown in Table 2. The ADF test results show that the original sequence of each variable presents a non-stationary state at the significance levels of $1 \%$ and $5 \%$. After the first-order difference treatment, all variables reject the original hypothesis at the significance level of $5 \%$.

Table 2. Results of ADF test and PP test.

\begin{tabular}{|c|c|c|c|c|c|c|}
\hline Sequence & $\begin{array}{c}\text { Significance } \\
\text { level of } 1 \%\end{array}$ & $\begin{array}{c}\text { Significance } \\
\text { level of } 5 \%\end{array}$ & $\begin{array}{c}\text { ADF } \\
\text { test value }\end{array}$ & Conclusion & $\begin{array}{c}\text { PP } \\
\text { test value }\end{array}$ & Conclusion \\
\hline$y$ & -4.004425 & -3.098896 & -2.310329 & Not stable & -2.317246 & Not stable \\
\hline$d y^{*}$ & -4.057910 & -3.119910 & -4.440576 & Stable & -4.393287 & Stable \\
\hline$e$ & -4.004425 & -3.098896 & -2.707704 & Not stable & -3.399822 & Stable \\
\hline$d e^{*}$ & -4.057910 & -3.119910 & -4.263613 & Stable & -4.537028 & Stable \\
\hline$t$ & -4.004425 & -3.098896 & 0.369753 & Not stable & 0.475790 & Not stable \\
\hline$d t^{*}$ & -4.057910 & -3.119910 & -3.819510 & Stable & -3.819510 & Stable \\
\hline$i$ & -4.004425 & -3.098896 & -2.136746 & Not stable & -2.215157 & Not stable \\
\hline$d i^{*}$ & -4.057910 & -3.119910 & -3.771070 & Stable & -4.291993 & Stable \\
\hline
\end{tabular}

$* d$ represents the first-order difference. 
The PP test results are similar. Except for environmental regulation, the original sequence of all variables presents a non-stationary state at the significance levels of $1 \%$ and $5 \%$. After first-order difference treatment, all variables reject the null hypothesis at the significance level of $5 \%$.

All the results above show that the first-order difference sequence of the variables in the sample period is stationary, thereby satisfying the cointegration test condition.

The highly operable EG test method is used to further analyze the dynamic cointegration relationship of the above-mentioned variables, and the OLS method is used to conduct regression tests on $y, e, t$ and $i$ with the results as follows:

$$
y=-0.1632+0.9087 e+0.0590 t+0.3257 i+u_{1 t}
$$

Testing the whole order $u_{l t}$ of the regression residual sequence shows that the ADF test value of $u_{l t}$ is -3.251188 , thereby rejecting the null hypothesis that it has a unit root at the significance level of $5 \%$ (3.098896) and drawing the conclusion that the residual error sequence is stable. The reciprocal root of the VAR model is smaller than 1 and thus, the structure of the model is relatively stable. Environmental regulation, technological progress and water resource consumption in the TI have a long-term cointegration relationship. To test the short-term effect and cointegration mechanism among variables, the error correction model is built with model (8) as the error correction term. The results are consistent with the cointegration test results.

\section{Impulse Response Function Analysis}

Given the stability of the VAR system, variables can be analysed by impulse measure function. On the basis of the cointegration relation analysis above, this study selects the generalised impulse response function to analyse the dynamic impact response among water consumption, environmental regulation and technological progress for understanding the influence of impact on variables in different periods. The response period is set as 10 . The specific results are shown in Table 3, and the impulse response diagram is shown in Fig. 2.

(1) Dynamic response relationship between water consumption and environmental regulation in the IT. As shown in Fig. 2a) and Table 3, the response curve of $y$ to a unit impact of $e$ in the entire impact response period is roughly M-shaped. Specifically, the response in the first phase is 0 . The value in the second phase reaches the maximum of 0.015377 with a relatively flat pace. Then, the impulse response value gradually declines to 0.007504. After short-term adjustment, the responses in the first to sixth phases show an overall upward
Table 3. Results of generalized impulse response analysis.

\begin{tabular}{|c|c|c|c|c|}
\hline \multirow{2}{*}{ Period } & \multicolumn{4}{|c|}{ Response of } \\
\cline { 2 - 5 } & $y$ to $e$ & $e$ to $y$ & $y$ to $t$ & $t$ to $y$ \\
\hline 1 & 0.000000 & -0.012052 & 0.000000 & -1.084623 \\
\hline 2 & 0.015377 & 0.102082 & 0.077460 & -2.357596 \\
\hline 3 & 0.007504 & 0.158362 & -0.021035 & 1.849444 \\
\hline 4 & 0.034545 & 0.064914 & 0.025303 & 3.862212 \\
\hline 5 & 0.025605 & 0.021997 & -0.028907 & 5.318634 \\
\hline 6 & 0.017389 & -0.010512 & 0.002484 & 5.015779 \\
\hline 7 & 0.008302 & 0.018203 & -0.012951 & 4.681259 \\
\hline 8 & 0.004958 & 0.025738 & -0.006896 & 4.843122 \\
\hline 9 & 0.007512 & 0.026005 & -0.012166 & 5.025067 \\
\hline 10 & 0.006608 & 0.012073 & -0.015239 & 5.238963 \\
\hline Accumulation & 0.1278 & 0.40681 & 0.008053 & 32.39226 \\
\hline
\end{tabular}

trend and reach a maximum value of 0.025605 in the entire response period in the fifth phase. After the sixth phase, the value shows a slow decline and reaches the minimum of 0.006608 in the tenth phase. Calculating the cumulative response value of $y$ during the analysis periods shows that the overall impact of $e$ on $\mathrm{y}$ in the current period is positive $(0.1278)$, which indicates that water consumption in the TI fluctuates with the improvement in environmental regulation but increases in the long run. In the unit impact effect of $e$ on water consumption in the TI, the first three periods show a rising trend and reach the maximum value in the third phase (0.158362). Subsequently, a significant downward trend with a negative value of -0.010512 is observed in the sixth phase. The value is increased to positive (0.018203) in the seventh phase. The upward trend holds until the ninth phase and then declines slowly. The accumulative response of this part is 0.40681, which indicates that the overall level of environmental regulation increases when water consumption in the TI is controlled.

(2) Dynamic response relationship between water consumption and technological progress in the TI. As shown in Fig. 2b) and Table 3, the first six periods in the entire impact response period show the characteristic of 'fluctuation alternation' and reach the maximum response value of 0.077460 in the second phrase. The value falls below 0 in the seventh phase and then declines relatively steadily. During the analysis periods, the cumulative response value of $y$ is 0.008053 , which indicates that technological progress can promote the effective improvement in water consumption in the TI. In terms of the impact of technological progress on water consumption in the TI, the first two periods show a downward trend and are always negative. In the second phase, the value falls to a minimum of 2.357596 . Then, the value shows an upward trend and reaches 
a)

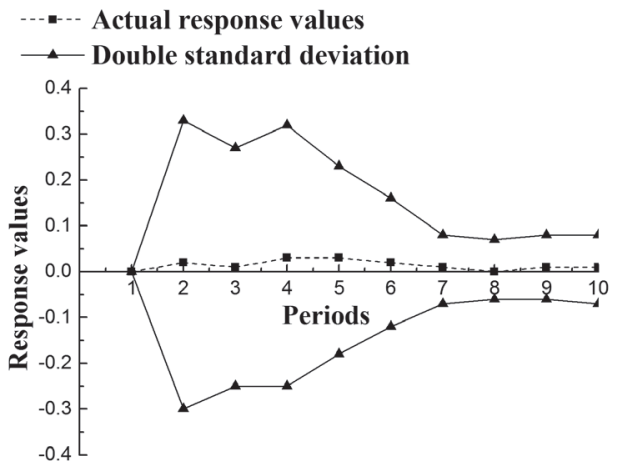

b)

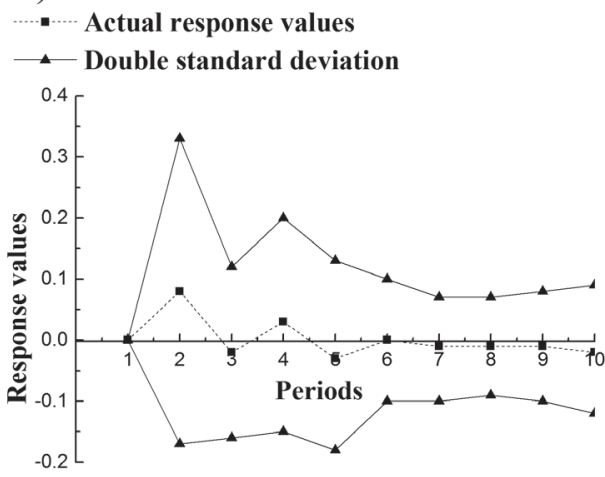

Fig. 2. Impulse response diagram.

a steady state after the sixth phase. The cumulative response value is 32.39226 , which shows that controlling water consumption in the TI can effectively promote the improvement in technical progress as its powerful backing.

\section{Forecast Error Variance Decomposition}

The VAR system is built for predictions. This part decomposes the prediction error variance of environmental regulation, technological progress and

Table 4. Results of prediction error variance decomposition.

\begin{tabular}{|c|c|c|c|c|}
\hline \multirow{2}{*}{ Period } & \multicolumn{4}{|c|}{ Variance decomposition of } \\
\cline { 2 - 5 } & $t$ to $y$ & $e$ to $y$ & $y$ to $e$ & $y$ to $t$ \\
\hline 1 & 5.290331 & 0.520506 & 0 & 0 \\
\hline 2 & 21.24664 & 26.95664 & 0.16429 & 4.168938 \\
\hline 3 & 26.92948 & 53.0393 & 0.178563 & 3.929557 \\
\hline 4 & 39.78996 & 55.09609 & 0.885758 & 4.221509 \\
\hline 5 & 54.43038 & 55.33545 & 1.257098 & 4.647711 \\
\hline 6 & 59.22649 & 55.13275 & 1.423451 & 4.615221 \\
\hline 7 & 62.91736 & 55.24178 & 1.457114 & 4.692057 \\
\hline 8 & 65.6874 & 55.55869 & 1.46965 & 4.714124 \\
\hline 9 & 68.19068 & 55.94743 & 1.499398 & 4.790469 \\
\hline 10 & 70.39098 & 56.00757 & 1.519141 & 4.906943 \\
\hline Mean & 47.40997 & 46.88362 & 0.985446 & 4.068653 \\
\hline
\end{tabular}
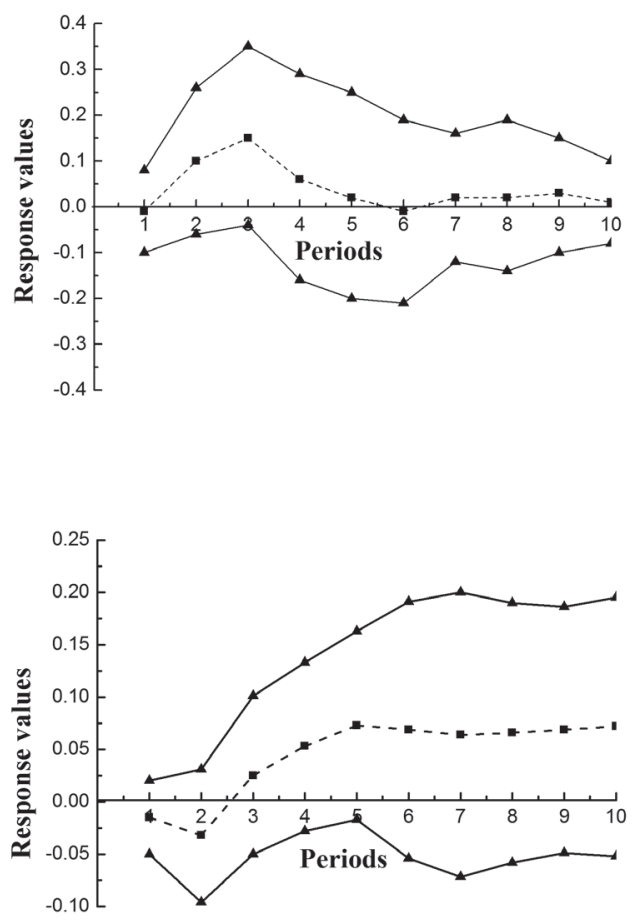

water resource consumption in the TI. The results are shown in Table 4. As shown in the table, the relative average contribution of environmental regulation and technological progress to water resource consumption in the TI is relatively high, with values of $46.88 \%$ and $47.41 \%$, respectively, which are less affected by themselves. This result shows that adjusting the intensity of environmental regulation and improving the level of technological progress can affect water resource consumption in the TI to a great extent. This finding also confirms that the comprehensive management level of water use in the TI needs to be improved in order to promote water conservation and emission reduction in the industry, promote green production and clean production and reduce water resource consumption in the TI, driven by the demand for new industrialisation. However, in the variance decomposition for environmental regulation and technology improvement, the average contribution of water consumption to environmental regulation and technological progress in the TI is relatively low, with values of $0.99 \%$ and $4.07 \%$, respectively. Therefore, the causes of improvement in environmental regulation and technological progress are complex. Water consumption in the TI is the main contributor to such improvement. The results are in accord with the reality of China's TI green development planning. 


\section{Conclusions}

After the decoupling model and the VAR model were established, an empirical analysis was conducted on the relationship among water resource consumption, environmental regulation and technological progress in China's TI. From the results, the following conclusions and policy implications were obtained:

(1) After a certain period of adjustment, a relatively significant decoupling is observed among environmental regulation, technological progress and water resource consumption in the TI. Among the 14 decoupling calculations from 2001 to 2014, the decoupling between environmental regulation and water resource consumption in the TI presented the periodic decoupling fluctuation state of "decoupling state gradually strengthens, decoupling state slows down, decoupling state is stable", and has shown a relatively stable strong decoupling in recent years. The decoupling between technological progress and water resource consumption in the TI presented the periodic decoupling fluctuation state of "decoupling state is bad, decoupling state is ideal, decoupling state in fluctuation". Technological progress effectively inhibits the increase in total water resource consumption in the TI. Therefore, the overall internal correlation between regulatory and technological innovation policies and the overall demonstration should be strengthened. Improvement in water use efficiency, total control of water resource consumption in the TI and the transformation and upgrading of the TI and green development should be promoted.

(2) Environmental regulation and technological progress in the TI significantly promote water resource consumption. In the short term, environmental regulation and technological progress have a lagged effect on water resource consumption in the TI. The increases in environmental regulation and technological progress exert evident driving effects on water resource consumption in the TI. In the long run, these driving effects will weaken gradually. The results of impulse response and variance decomposition of prediction error indicate that adjusting the intensity of environmental regulation and improving the level of technological progress have a fluctuating impact on water resource consumption in the TI in the short term. However, the impact stabilises in the long term, and environmental regulation and technological progress can increase water resource consumption in the TI. All these results show that China's current policies on environmental protection and promotion of $\mathrm{R} \& \mathrm{D}$ and innovation are very effective. The policies on environmental protection should be firmly implemented, R\&D and innovation should be evaluated and the level of human capital and the efficiency of transformation of new technological achievements should be continuously improved in the context of ecological and environmental protection in order to achieve sustainable and high-quality development of the TI.
(3) The increase in water resource consumption in the TI can effectively promote the strengthening of regulations and the development of technological progress. Environmental regulation is a process in which the technology advances continuously. The increase in overall water resource consumption in the TI affects the decision-making of environmental management departments and improves the level of environmental regulation. The increase in water resource consumption in the TI is also a part of technological progress, which has a certain driving action. In the market economy, the marginal increase in water resource consumption in the TI will firstly affect the efficiency of other sectors in the entire industry chain in the TI and then drive the technological progress of the entire economy. The impulse response and forecast error variance decomposition results show the ascension of the TI's water consumption of environmental regulation on technical progress. The strength in the ascension has a certain but limited effect because many factors affect environmental regulations and technological progress. Water resource consumption is only one of them and is insignificant. Thus, water resource utilisation efficiency is not the main purpose and method to promote the strengthening of environmental regulation and technological progress. The supervision means of the entire lifecycle of water consumption in the TI should be strengthened, and research and development of and investment in advanced technology and technology and equipment for water conservation and pollution control in the TI should be promoted.

\section{Acknowledgements}

This work was supported by the General Project of Humanities and Social Science Research of the Ministry of Education of China (19YJCZH092), Key projects of the national social science fund (19AZD004), the National Statistical Science Research Project of China (2018LY29), the National College Students' Innovative Entrepreneurial Training Program of China (201810338043) and the Science Foundation of Zhejiang Sci-Tech University (18092252-Y).

\section{Conflict of Interest}

The authors declare no conflict of interest.

\section{References}

1. Ministry of Industry and Information Technology of the People's Republic of China. The 13th Five-Year Planning of Textile Industry. http://www.miit.gov.cn/n1146290/ n4388791/c5267286/content.html (accessed on 01.01.2018) [In Chinese]. 
2. Annual Statistic Report on Environment in China. http:// data.cnki.net/yearbook/Single/N2017050140 (accessed on 01.01.2018) [In Chinese].

3. RUIZ-VANOYE J.A., BARRERA-CÁMARA R., DÍAZPARRA O., FUENTES-PENNA A., ORTEGA J.P., LORANCA B.B., SAENZ A.C., SANTIAGO-PÉREZ J.C. Surveying the optimization problems of water distribution networks. Polish Journal of Environmental Studies, 27 (4), 1425,2018

4. YUE W., CAI Y., XU L., YANG Z., YIN X., SU M. Industrial water resources management based on violation risk analysis of the total allowable target on wastewater discharge. Scientific Reports, 7 (1), 5055, 2017.

5. TUAN P.T., DUNG M.T., DUC P.T., TRANG H.M., KHAI N.M., PHAM T.T. Industrial water mass balance as a tool for water management in industrial parks. Water Resources and Industry, 13, 14, 2016.

6. LI Y., LI W., WANG B., LIU X.W., XIE Y.L., LIU L. An inexact multi-objective programming model for water resources management in industrial parks of Binhai new area, China. Water Science and Technology, 72 (10), 1879, 2015.

7. ASEFA T., CLAYTON J., ADAMS A., ANDERSON D. Performance evaluation of a water resources system under varying climatic conditions: reliability, resilience, vulnerability and beyond. Journal of Hydrology, 508, 53, 2014.

8. RAMOS M.A., BOIX M., AUSSEL D., MONTASTRUC L., DOMENECH S. Water integration in eco-industrial parks using a multi-leader-follower approach. Computers and Chemical Engineering, 87, 190, 2016.

9. ALNOURI S.Y., LINKE P., EL-HALWAGI M. A synthesis approach for industrial city water reuse networks considering central and distributed treatment systems. Journal of Cleaner Production, 89, 231, 2015.

10. GENG Y., CÔTÉ R., TSUYOSHI F. A quantitative water resource planning and management model for an industrial park level. Regional Environmental Change, 7 (3), 123, 2007.

11. WANG Y., BIAN Y., XU H. Water use efficiency and related pollutants' abatement costs of regional industrial systems in China: A slacks-based measure approach. Journal of Cleaner Production, 101, 301, 2015.

12. LI Y., LU L., TAN Y., WANG L., SHEN M. Decoupling water consumption and environmental impact on textile industry by using water footprint method: A case study in China. Water, 9, 124, 2017

13. HU J.L., WANG S.C., YEH F.Y. Total-factor energy efficiency of regions in China. Resources Policy, 31, 217, 2006.

14. TAPIO P. Towards a theory of decoupling: Degrees of decoupling in the EU and the case of road traffic in Finland between 1970 and 2001. Transport Policy, 12 (2), 137, 2005.

15. HU J.B., GUI S.S., ZHANG W. Decoupling analysis of China's product sector output and its embodied carbon emissions - An empirical study based on non-competitive I-O and Tapio decoupling model. Sustainability, 9 (5), 815, 2017.

16. GOU W.B., CHEN Y. Assessing the efficiency of China's environmental regulation on carbon emissions based on Tapio decoupling models and GMM models. Energy Reports, 4, 713, 2018.

17. DASH D.P., SETHI N., BAL D.P. Is the demand for crude oil inelastic for India? Evidence from structural VAR analysis. Energy Policy, 118, 552, 2018
18. CUI H.R., WU R.R., ZHAO T. Sustainable development study on an energy-economic-environment system based on a vector autoregression model in Shanxi, China. Polish Journal of Environmental Studies, 28 (3), 1623, 2019.

19. TIWARI A.K. A structural VAR analysis of renewable energy consumption, real GDP and $\mathrm{CO}_{2}$ emissions: Evidence from India. Economics Bulletin, 31 (2), 1793, 2011.

20. ZHANG Y., XU J.X., ZHAI L. Are there bubbles in the defence sector of China's stock market (2005-2016)? New evidence from sequential ADF tests. Defence and Peace Economics, (1), 1, 2018.

21. WEN L., ZHANG X. $\mathrm{CO}_{2}$ emissions in China's Yangtze River economic zone: A dynamic vector autoregression approach. Polish Journal of Environmental Studies, 28 (2), 923, 2019.

22. AMIN S.B., ALAM T. The relationship between energy consumption and sectoral output in Bangladesh: An empirical analysis. The Journal of Developing Areas, 52 (3), 39, 2018

23. ZAHNG F., SONG X.N., XUE H.F., DONG H.Z. Decoupling relationship and dynamic response between industrial water intensity, environmental regulation and technological progress. China Population Resources and Environment, 27 (11), 193, 2017 [In Chinese].

24. DUBE A.K., OZKAN B., GOVINDASAMY R. Analyzing the export performance of the horticultural sub-sector in Ethiopia: ARDL bound test cointegration analysis. Horticulturae, 4 (4), 34, 2018

25. JUODIS A. Rank based cointegration testing for dynamic panels with fixed T. Empirical Economics, 55 (2), 349, 2018.

26. HARVEY D.I., KELLARD N.M., MADSEN J.B., WOHAR M.E. Long-run commodity prices, economic growth, and interest rates: 17 th century to the present day. World Development, 89, 57, 2017.

27. KARAMÉ F. An algorithm for generalized impulseresponse functions in Markov-switching structural VAR. Economics Letters, 117 (1), 230, 2012.

28. ZAHNG F., XUE H.F., SHI Z.W. The effect of resource endowment and environmental regulation on green development of manufacturing industry. Scientific Decision Making, 05, 60, 2018 [In Chinese].

29. RUBASHKINA Y., GALEOTTI M., VERDOLINI E. Environmental regulation and competitiveness: Empirical evidence on the Porter Hypothesis from European manufacturing sectors. Energy Policy, 83, 288, 2015.

30. BECKER R.A., JR. C.P., SHADBEGIAN R.J. Do environmental regulations disproportionately affect small businesses? Evidence from the pollution abatement costs and expenditures survey. Journal of Environmental Economics and Management, 66, 523, 2013

31. HU J.F., WANG Z., LIAN Y.H., HUANG Q.H Environmental regulation, foreign direct investment and green technological progress-evidence from Chinese manufacturing industries. International Journal of Environmental Research and Public Health, 15, 221, 2018.

32. FU J.Y., HU J., CAO X. Different sources of FDI, environmental regulation and green total factor productivity. Journal of International Trade, 427 (07), 138, 2018 [In Chinese].

33. FU J.Y., LI L.S. A case study on the environmental regulation, the factor endowment and the international competitiveness in industries. Management World, 10, 87, 2010 [In Chinese]. 
34. FU J.Y., LI L.S. FDI, Environmental regulation and pollution haven effect: empirical analysis of China's provincial panel data. Journal of Public Management, 7 (3), 65, 2010 [In Chinese].

35. FENG M., YU K.H., WANG X.Y., HAO R. An empirical analysis on the influence of technological innovation on performance of iron and steel industry. Journal of Scientifics and Industrial Research, 76, 397, 2017.

36. ANTONELLI C., QUATRARO F. The effects of biased technological changes on total factor productivity: A rejoinder and new empirical evidence. The Journal of Technology Transfer, 47 (10), 1686, 2014.

37. FEDER C. The effects of disruptive innovations on productivity. Technological Forecasting and Social Change, 126, 186, 2018.

38. BI K.X., HUANG P., WANG X.X. Innovation performance and influencing factors of low-carbon technological innovation under the global value chain: A case of Chinese manufacturing industry. Technological Forecasting and Social Change, 111, 275, 2016.

39. LI J., STRANGE R., NING L.T., SUTHERLAND D. Outward foreign direct investment and domestic innovation performance: Evidence from China. International Business Review, 25, 1010, 2016.

40. HONG J., FENG B., WU Y.R., WANG L.B. Do government grants promote innovation efficiency in China's high-tech industries? Technovation, 57, 4, 2016.

41. LUINTEL K.B., KHAN M. A quantitative reassessment of the finance-growth nexus: Evidence from a multivariate VAR. Journal of Development Economics, 60 (2), 381, 1999.

42. LU X.D., LIAN Y.J. Estimation of total factor productivity of industrial enterprises in China: 1999-2007. China Economic Quarterly, 11 (2), 541, 2012 [In Chinese].

43. Yu S, SONG L. Re-estimation of firms' total factor productivity in China's iron and steel industry. China Economic Review, 24 (1), 178, 2013.

44. CHANG M.C., HU J. L., CHANG H.C. Resource efficiency and productivity changes in the G7 and BRICS nations. Polish Journal of Environmental Studies, 27 (6), 2463. 2018.

45. WU Y.R. The role of productivity in China's growth: New estimates. China Economic Quarterly, 7 (3), 827, 2008 [In Chinese]. 
